\title{
The Preparation and Fluorescence of Conjugated Polymer Nanoparticles with Triphenylamine Derivatives
}

\author{
Yue-Hong ZHU ${ }^{1,3}$, Xian ZHANG ${ }^{1,3,{ }^{,},}$, Yuan-An QIN ${ }^{1,3}$, Zhao-E LIU² \\ ${ }^{1}$ School of Materials Science and Engineering, Qilu University of Technology, Jinan 250353, China \\ ${ }^{2}$ Qilu Hospital of Shandong University, Jinan 250012, China \\ ${ }^{3}$ Shandong Provincial Key Laboratory of Processing and Testing Technology of Glass and \\ Functional Ceramics, Shandong Provincial Key Laboratory of Fine Chemicals, Qilu University of \\ Technology, Jinan 250353, China \\ azhangx@qlu.edu.cn \\ ${ }^{*}$ Corresponding author
}

Keywords: Synthesize, Conjugated polymer Nanoparticles, Fluorescence, Morphology.

\begin{abstract}
The conjugated polymers TEB1 and TEB2 were synthesized by Wittig and Wittig-Horner reaction, and the conjugated polymer nanoparticles CPNs1 and CPNs2 were prepared by reprecipitation method with TEB1 and TEB2, respectively. Moreover, the morphology and fluorescence of CPNs were investigated. The synthetic results indicated that the average molecular weight was improved effectively by Wittig-Horner reaction. CPNs2 with a higher average molecular weight showed a better feature and bright fluorescence.
\end{abstract}

\section{Introduction}

Owing to their large $\pi$-conjugated backbone and delocalized structure, conjugated polymers (CPs), a kind of fluorescent material with high fluorescence quantum yields and outstanding photostability $[1,2]$, have been widely applied in material science, biology and chemistry fields. At present, CPs can be divided into PF, PPV, PPE [3] and their derivatives in terms of the backbone structure difference. And palladium-catalyzed coupling reactions (Suzuki coupling, Heck coupling and Sonogashira coupling) tend to be used to prepare CPs [3]. Moreover, nanoparticles based on CPs show greatly potential applications in biosensor and optoelectronic device, and so on [4]. Conjugated polymer nanoparticles (CPNs) have attracted a board attention from home and abroad scholar because of their easy synthesis, less toxicity and more biocompatibility [5]. In the past few years, their preparation methods and functional modifications have been explored [6-8]. In this paper, novel fluorescent conjugated polymers (TEB) were synthesized by Wittig and Wittig-Horner reaction, and the average molecular weight was improved effectively by Wittig-Horner reaction. The CPNs1 and CPNs2 were prepared by reprecipitation method with TEB1 and TEB2, respectively. Furthermore, the morphology and fluorescence of CPNs were investigated.

\section{Experimental}

\section{Chemicals}

Triphenylamine was purchased from Aladdin. Other chemicals were AR grade without further purification. All solvents were anhydrous grade after further purification. A tetrahydrofuran (THF) solution was dealt with sodium and prepared immediately before use. Silica gel with a $120 \AA$ mean pore size and particle size of $10 \mathrm{um}$ for column chromatography was purchased from Qingdao Haiyang Chemical Co., Ltd.

\section{Instruments}

1H NMR spectra were recorded on a Bruker Avance 400 spectrometer operating at $400 \mathrm{MHz}$ with TMS internal standard as a reference for the chemical shifts. Infrared spectra were recorded on a 
Nicolet NEXUS 670 FT-IR spectrometer using a liquid-nitrogen-cooled detector. The samples were mixed with $\mathrm{KBr}$ to form a disk. The UV-visible-near-IR absorption spectra of dilute solutions were recorded on a TU-1800 spectrophotometer using a quartz cuvette with a $1 \mathrm{~cm}$ path length. One-photon fluorescent spectra were recorded with a HITRCHIF-4500 fluorescence spectrometer. The morphology of CPNs was observed using a H800 transmission electron microscope (TEM) at an acceleration voltage of $200 \mathrm{kV}$.

\section{Synthesis}

The synthetic route to the expected compound and CPNs was depicted in Scheme 1.<smiles>c1ccc(N(c2ccccc2)c2ccccc2)cc1</smiles><smiles>CCc1ccc(N(c2ccccc2)c2ccc(C=O)cc2)cc1</smiles>

(1)

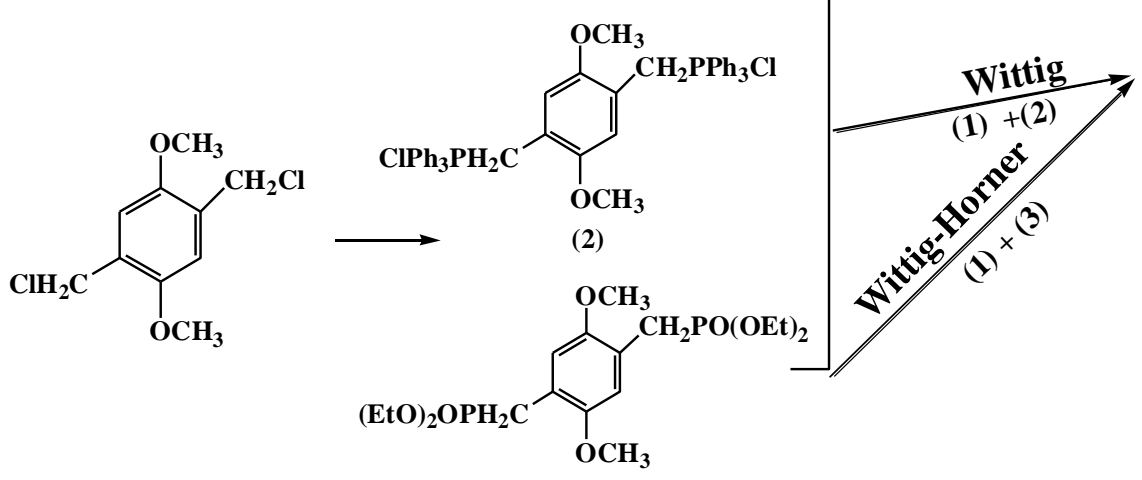

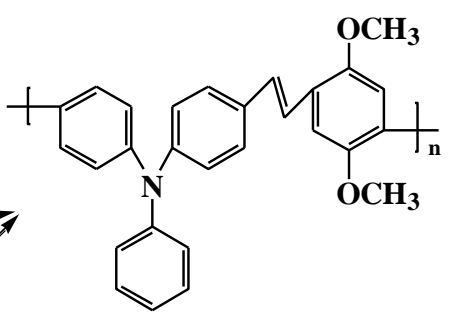

TEB

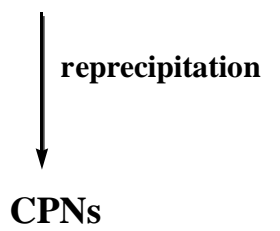

(3)

Scheme 1. The synthetic route of CPNs with TEB

4, 4'-diformyltriphenylamin

$(1)$,

$[(2$,

5-dimethoxy-1,

4-phenylene)] bis-(methylene)]bistriphenylphosphonium dichloride (2) and [4-(Diethoxy-phosphorylmethyl)-2, 5-dimethoxybenzyl]-phosphonic Acid Diethyl Ester (3) were synthesized according to the method reported in literatures $[9,10,11] .{ }^{1} \mathrm{H}$ NMR of the intermediate $(1)(400 \mathrm{MHz}, \mathrm{CDCl} 3, \mathrm{TMS}) \delta(\mathrm{ppm})$ : $9.91(\mathrm{~s}, 2 \mathrm{H}), 7.79(\mathrm{~d}, J=8.2 \mathrm{~Hz}, 4 \mathrm{H}), 7.50-7.33(\mathrm{~m}, 2 \mathrm{H}), 7.27(\mathrm{~s}, 7 \mathrm{H}) .{ }^{1} \mathrm{H}$ NMR of the intermediate (2) $\left(\mathrm{CDC1}_{3}, 400 \mathrm{MHz}, \mathrm{TMS}\right) \delta(\mathrm{ppm}): 7.74(\mathrm{t}, J=6.83 \mathrm{~Hz}, 30 \mathrm{H}), 6.59(\mathrm{~s}, 2 \mathrm{H}), 5.27(\mathrm{~d}, J=16.2 \mathrm{~Hz}, 4 \mathrm{H})$, 2.98(s, $6 \mathrm{H}) .{ }^{1} \mathrm{H}$ NMR of the intermediate (3) (400 MHz, DMSO, TMS) $\delta(\mathrm{ppm}): 6.88$ (s, $\left.2 \mathrm{H}\right), 3.92$ $(\mathrm{m}, 8 \mathrm{H}), 3.73(\mathrm{~d}, J=16.3 \mathrm{~Hz}, 6 \mathrm{H}), 3.13(\mathrm{~d}, J=20.2 \mathrm{~Hz}, 4 \mathrm{H}), 1.16(\mathrm{t}, J=7.0 \mathrm{~Hz}, 12 \mathrm{H}) . \mathrm{Mp}: 115^{\circ} \mathrm{C}$.

Procedure for the Synthesis of the Conjugated Polymer TEB. A mixture including compound (2) (1. $52 \mathrm{~g}, 2.0 \mathrm{mmol})$ or compound (3) $(0.88 \mathrm{~g}, 2.0 \mathrm{mmol})$ and dry tetrahydrofuran (THF) (10 mL) was added to a three-necked bottle and stirred for $30 \mathrm{~min}$ at $0{ }^{\circ} \mathrm{C}$ under nitrogen atmosphere. Potassium tert-butoxide (1.3 g, $10 \mathrm{mmol})$ dissolved in THF was dropwise added to the mixture and stirred for $20 \mathrm{~min}$. Then the intermediate $1(0.6 \mathrm{~g}, 2.0 \mathrm{mmol})$ was added into the reaction system at r.t. The mixture solution was stirred for 2 days under nitrogen atmosphere. Then the solvent was removed under reduced pressure. The residue was dissolved in dichloromethane and washed with methyl alcohol for three times. The yellow powers were obtained with a yield of $50.4 \%$. ${ }^{1} \mathrm{H} \mathrm{NMR}(400 \mathrm{MHz}$, DMSO) $\delta(\mathrm{ppm}): 7.87$ - $6.43(\mathrm{~m}, 17 \mathrm{H}), 3.95-3.40$ (m, $6 \mathrm{H})$. IR (KBr) v/ $\mathrm{cm}^{-1}: 3010 \mathrm{~cm}^{-1}(=\mathrm{C}-\mathrm{H})$, $1730 \mathrm{~cm}^{-1}(\mathrm{C}=\mathrm{C}) ; 1583 \mathrm{~cm}^{-1}, 1495 \mathrm{~cm}^{-1}, 1407 \mathrm{~cm}^{-1}$ (Ar, C-H); $1039 \mathrm{~cm}^{-1}\left(-\mathrm{OCH}_{3}, \mathrm{C}-\mathrm{O}\right)$. GPC (polystyrene calibration) of TEB with Wittig reaction by compound 1 and 2 (TEB 1): $M_{w} / M_{n}=1.103$, $M_{z} / M_{n}=1.274 ; M_{n}=2087 ; M_{w}=2301 ; M_{z}=2659$; GPC of TEB with Wittig- Horner reaction by compound 1 and 3 (TEB 2): $M_{w} / M_{n}=1.389, M_{z} / M_{n}=2.510 ; M_{n}=10690 ; M_{w}=14850 ; M_{z}=26830$.

Procedure for the Preparation of CPNs. The conjugated polymer TEB was first dissolved in tetrahydrofuran (THF) to make a stock solution of $1 \mathrm{mg} / \mathrm{mL}$, the solution was diluted to a 
concentration of $50 \mu \mathrm{g} / \mathrm{mL}$, and then quickly added to $10 \mathrm{~mL}$ of high purity water in a bath sonicator. The THF was removed by nitrogen stripping. The solution was concentrated to $5 \mathrm{~mL}$ on a $90{ }^{\circ} \mathrm{C}$ hotplate by continuous nitrogen stripping followed by filtration through a 0.2 micron filter. The CPNs were formed due to the significant change in solubility from benign to poor [12]. The CPNs 1 and CPNs 2 were obtained with TEB 1 and TEB 2, respectively.

\section{Results and Discussion}

\section{Study of the Procedure for Preparing Conjugated Polymer TEB}

TEB 1 and TEB 2 were prepared by Wittig and Wittig-Horner reaction, respectively. In comparison to the phosphonate (2), the phospholipid phosphatide (3) possesses the advantages of low stereo-hindrance effect and high flexibility [13], which increased its reaction ability with aldehyde groups. The results indicated that the obtained average molecular weight by Wittig-Horner reaction was greatly improved (from $M_{n}=2087$ in Wittig reaction to $M_{n}=10690$ in Wittig-Horner reaction). Accordingly, the increase of average molecular weight will affect on the morphology of CPNs.

\section{The Morphology of CPNs}

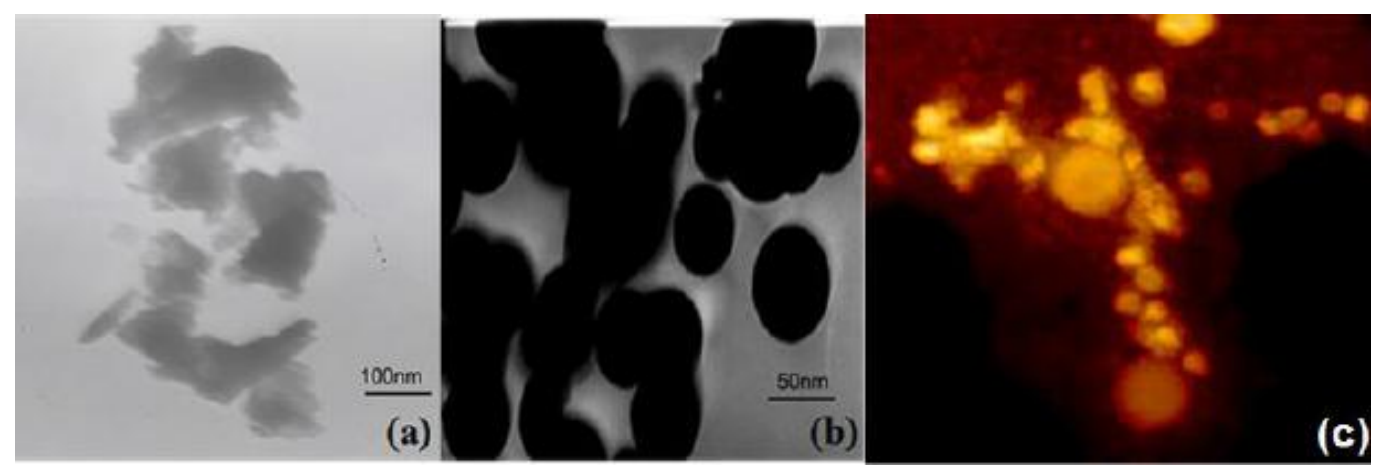

Fig. 1. The TEM images of CPNs1 (a) and CPNs2 (b); the AFM images of CPNs2 (c)

The morphology and structure of CPNs prepared with different average molecular weight of TEB 1 or TEB2 were presented in Figure 1. As shown in Figure 1 (a), some irregular aggregates can be observed for CPNs1. Whereas, spherical particles were obviously found despite of slight adhesion in Figure 1 (b) and 1 (c), and the average particle sizes were less than $50 \mathrm{~nm}$ in diameter (Figure 1 (b) and 1 (c)). Moreover, the bright light was found in Figure 1(c). The reason may be attributed to the different average molecular weight. The polymer chain of TEB 1 only contains $4 \sim 5$ repeat units, and the CPNs 1 prepared with the shorter chain easily occurred aggregation. However, the CPNs 2 were prepared with the longer chain by TEB 2 including 20 25 repeat units can form bigger nanoparticles and reduce the aggregation degree, so the spherical nanoparticles were obtained with a higher average molecular weight of TEB 2. Of course, it is unfavorable to obtain the ideal morphology for CPNs if the average molecular weight of a conjugated polymer was too high.

\section{Linear Absorption and One-photon Fluorescence}

The absorption and one-photon fluorescent spectra of CPNs 1 and CPNs 2 in THF with a concentration of $0.1 \mu \mathrm{g} / \mathrm{mL}$ are shown in Fig. 1 (a) and 1 (b), and the correlative data are summarized in Table 1. Quantum yields $(\Phi)$ of CPNs were determined with a reference method by using coumarin 307 as the standard [14]. From Fig.1, one can see that the shapes of the absorption and fluorescent spectra are almost coincident. But the UV absorption peak and the fluorescent emission peak of CPN 2 were red-shifted of $20 \mathrm{~nm}$ and $5 \mathrm{~nm}$ in comparison to that of CPN 1, respectively. In addition, the quantum yield of CPN 2 was 2 times larger than that of CPN 1. The possible reason was the enlargement of the delocalized system. According to molecular orbital theory, the energy of bonding orbital were raised with the increase of the conjugated double bond numbers, whereas the energy of 
anti-bonding orbital gradually decreased, and the energy $\Delta \mathrm{E}$ needed for $\pi$ electron transition decreased, so the absorption and fluorescent emission peaks occurred red-shifts.
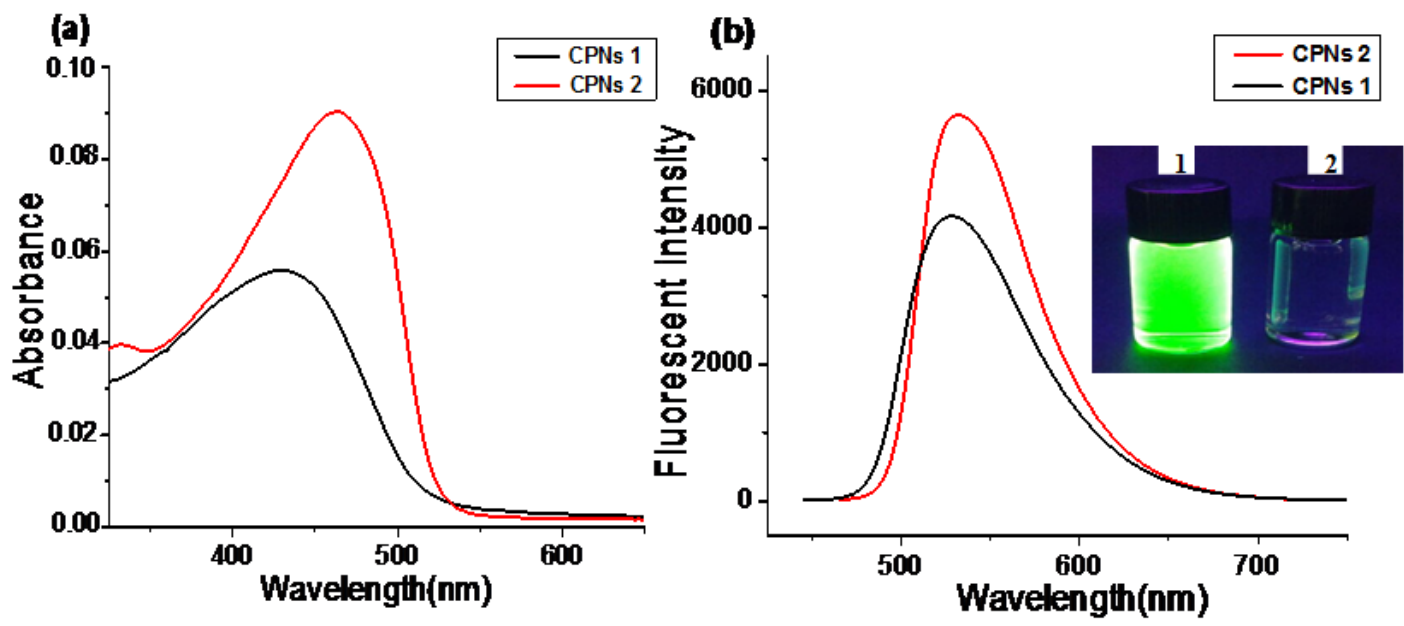

Fig. 2. The UV (a) and one-photon (b) spectra of CPNs $(0.1 \mu \mathrm{g} / \mathrm{mL})$ in THF; Inset in Figure 2(b): the photographs of CPNs1 (1) and CPNs2 (2) in THF under UV illumination (365 nm).

Tab. 1. The absorption spectra and one-photon related photophysical data of different systems[a]

\begin{tabular}{cccc}
\hline & $\lambda_{\max }^{U V}$ & $\lambda_{\max }^{O P}$ & $\Phi$ \\
\hline CPNs 1 & 434 & 527 & 0.26 \\
CPNs 2 & 454 & 532 & 0.54 \\
\hline
\end{tabular}

[a] All data were measured with a concentration of $0.1 \mu \mathrm{g} / \mathrm{mL}$ in $\mathrm{THF} ; \lambda_{\max }^{U V}$ and $\lambda_{\max }^{O P}$ are linear absorption and one-photon fluorescent peaks; $\Phi$ is one-photon fluorescent quantum yield determined using coumarin 307 as the standard; The uncertainty is $\pm 10 \%$.

\section{Summary}

In summarize, fluorescent conjugated polymers and their nanoparticles have been prepared, and the average molecular weight was improved effectively by Wittig-Horner reaction. The morphology and fluorescence of CPNs were investigated. The results showed that the properties of CPN 2 were superior to that of CPN 1. The spherical particle sizes of CPNs2 were less than $50 \mathrm{~nm}$ in diameter, and the quantum yield of CPN 2 was 2 times larger than that of CPN 1. It was considered that the better feature and fluorescence will be obtained if the molecular weight was properly enhanced.

\section{Acknowledgement}

This work was supported by for National Natural Science Foundation of China (No. 51403111, 21276149, 51303097), the Natural Science Foundation of Shandong Province (ZR2012EMM009, ZR2012EMZ003) and Program for Scientific research innovation team in Colleges and universities of Shandong Province.

\section{References}

[1]S. W. Thomas, G. D. Joly and T. M. Swager, Chemical Reviews, 2007, 107, 1339-1386. 
[2]H. Wang, Z. Li, P. Shao, J. Qin and Z.-1. Huang, The Journal of Physical Chemistry B, 2009, 114, 22-27.

[3]Feng, L.; Zhu, C.; Yuan, H.; Liu, L.; Lv, F.; Wang, S. Chemical Society Reviews, 2013, 42, 6620-6633.

[4]Alsalhi, M. S.; Alam, J.; Dass, L. A.; Raja, M. Int J Mol Sci, 2011, 12, 2036-54.

[5]Tuncel, D.; Demir, H. V. Nanoscale, 2010, 2, 484-494.

[6] K. Li and B. Liu,J. Mater. Chem., 2012, 22, 1257-1264.

[7]A. Kaeser and A. P. H. J. Schenning, Adv. Mater., 2010, 22, 2985-2997.

[8]K. Y. Pu and B. Liu, Adv. Funct. Mater., 2011, 21, 3408-3423.

[9]O. Mongin, T. Mallegol, S. Gmouh, M. A. Meziane, M. Blanchard-Desce, Synthesis, 2005, 1771-1774.

[10]Ndayikengurukiye, H.; Jacobs, S.; Tachelet, W. Tetrahedron, 1997, 53, 13811-13828.

[11]Park, Y. I.; Kuo, C. Y.; Martinez, J. S.; Park, Y. S.; Postupna, O.; Zhugayevych, A.; Kim, S.; Park, J.; Tretiak, S.; Wang, H. L. ACS Appl Mater Interfaces , 2013, 5, 4685-95.

[12]Wu, C.; Jin, Y.; Schneider, T.; Burnham, D. R.; Smith, P. B.; Chiu, D. T. Angewandte Chemie, 2010, 122, 9626-9630.

[13]Iwase, Y.; Kamada, K.; Ohta, K.; Kondo, K. Journal of Materials Chemistry, 2003, 13, 1575.

[14]A. Crosby, J. N. Demas, The Journal of Physical Chemistry, 1971, 75, 991-1024. 